\title{
Electronic spectroscopy of the $\beta$-carboline derivatives nitronorharmanes, nitroharmanes, nitroharmines and chloroharmines in homogeneous media and in solid matrix
}

\author{
Olga I. Tarzi, María A. Ponce, Franco M. Cabrerizo, Sergio M. Bonesi, * and Rosa Erra- \\ Balsells* \\ CIHIDECAR-CONICET, Departamento de Química Orgánica, Facultad de Ciencias Exactas y \\ Naturales, Universidad de Buenos Aires, Pabellón 2, 3er Piso, Ciudad Universitaria, 1428 - \\ Buenos Aires, Argentina \\ E-mail: smbonesi@qo.fcen.uba.ar anderra@qo.fcen.uba.ar
}

Dedicated to Prof. Dr. Rosa M. de Lederkremer on occasion of her $70^{\text {th }}$ anniversary

\begin{abstract}
Electronic spectra (absorption, fluorescence and phosphorescence emission spectra) of nitro- $\beta$ carboline derivatives (nitronorharmanes, nitroharmanes and nitroharmines) in acetonitrile and in methanol solution at $298 \mathrm{~K}$ and in solid matrix at $77 \mathrm{~K}$ have been recorded and compared with those of the corresponding $\beta$-carbolines and chloroharmine derivatives. The electronic absorption spectra of triplet transients of these $\beta$-carbolines, the triplet lifetime, $\tau_{\mathrm{T}}$, and the intersystem crossing quantum yield, $\varphi_{\text {isc }}$, were measured by Laser Flash Photolysis at $298 \mathrm{~K}$. The dynamic properties of the lowest excited singlet and triplet states $\left(\tau_{\mathrm{f}}, \tau_{\mathrm{p}}, \varphi_{\mathrm{f}}\right.$ and $\left.\varphi_{\mathrm{p}}\right)$ have been measured in the same experimental conditions. From these data, the radiative and radiationless rate constants $\left(k_{\mathrm{f}}^{\mathrm{o}}, k_{\mathrm{isc}}\right.$ and $\left.k_{\mathrm{ic}}\right)$ were derived. The intramolecular spin - orbital coupling effect on the spectroscopic data and photophysical rate constant were also analyzed.
\end{abstract}

Keywords: $\beta$-Carbolines, Nitro- $\beta$-carbolines, Spectroscopic and photophysics

\section{Introduction}

As part of our study of the photochemistry of $\beta$-carbolines, $9 \mathrm{H}$-pyrido[3,4-b]indoles, ${ }^{1}$ and their potential use as matrices (photosensitizers) in matrix assisted ultraviolet laser desorption / ionization mass spectrometry (UV-MALDI MS), ${ }^{2}$ we decided to examine the behavior of substituted $\beta$-carbolines. We have recently described commercial $\beta$-carbolines (norharmane, harmane and harmine) as quite efficient UV-MALDI matrices. ${ }^{2}$ As substituted $\beta$-carbolines, nitro- $\beta$-carbolines were selected because, as it is known, for aromatic molecules, nitro group as 
substituent might induce modifications of the acid-base properties in the ground and electronic excited state, on the nature $\left(\pi, \pi^{*} ; \mathrm{n}, \pi^{*}\right)$, multiplicity (singlet, $\mathrm{S}_{1} ;$ triplet, $\left.\mathrm{T}_{1}\right)$, lifetime $\left(\tau_{\mathrm{S} 1} ; \tau_{\mathrm{T} 1}\right)$ and efficiency of population $(\varphi)$ of the electronic excited states without affecting much their photostability. 3,4

As it is well known, UV-MALDI $\mathrm{MS}^{5,6}$ has become a versatile and important tool for the determination of molecular masses and structure of macromolecules such as synthetic polymers ${ }^{7}$ and biopolymers. ${ }^{8,9}$ The principle of UV-MALDI involves ionizing macromolecules for MS analysis by diluting them in a suitable matrix of small organic molecules which absorb the UVlaser photons. Thus, the knowledge of the photochemistry and photophysics of the potential UVMALDI matrices is essential for the comprehension of the UV-MALDI processes which occur after the electronic excitation of the matrix.

The effect of heavy atoms on the photophysical properties of aromatic compounds has been of great interest. ${ }^{3,4,10}$ An halogen with high atomic number (heavy atom) attached directly to an aromatic compound can reduce significantly the fluorescence quantum yield and this effect is called the intramolecular heavy atom effect (HAE). ${ }^{10-15}$ The spin-orbital coupling mechanism of the heavy atom enhances the rate of intersystem crossing to the triplet state. ${ }^{12,15,16}$ Bromine and iodine atoms, as heavy atoms, have been preferentially used in order to study both intramolecular and intermolecular HAE. ${ }^{3,410-16}$ Furthermore, carbonyl and nitro groups attached to aromatic compounds also show a spin - orbital coupling mechanism that reduces significantly the fluorescence quantum yield of the aromatic compound and enhances the intersystem crossing process. 3,4

In the present work the effect of the nitro group as substituent on the fluorescence $\left(\varphi_{\mathrm{f}}, \tau_{\mathrm{f}}, \tau_{\mathrm{f}}^{0}\right.$, $\left.\mathrm{k}_{\mathrm{f}}^{0}\right)$ and phosphorescence $\left(\varphi_{\mathrm{p}}, \tau_{\mathrm{p}}, \mathrm{k}_{\mathrm{p}}^{0}\right)$ parameters of several $\beta$-carboline derivatives is investigated: i) in acetonitrile and in methanol at $298 \mathrm{~K}$; ii) in the same solvents in the presence of added mineral acids at $298 \mathrm{~K}$; iii) in a mixture of isopropanol - ethyl ether (1:1; v:v) at $77 \mathrm{~K}$ and iv) in a mixture of isopropanol - ethyl ether (1:1) with added mineral acids at $77 \mathrm{~K}$ by using time correlated single photon counting technique and phosphorescence lifetime spectroscopy. Also, the electronic absorption spectra of the triplet transient, the triplet lifetime $\left(\tau_{\mathrm{T}}\right)$ and the intersystem crossing quantum yield $\left(\varphi_{\text {isc }}\right)$ of the $\beta$-carboline derivatives were investigated by Laser flash photolysis technique at $298 \mathrm{~K}$. Scheme 1 shows the $\beta$-carboline derivatives studied and in order to compare the effect of a light atom as substituent (light substituent $=\mathrm{H}$ ) and a spin - orbital coupling group as substituent (heavy substituent $=\mathrm{NO}_{2}$ ) in the same $\beta$-carboline moiety. Thus, the spectroscopic data for harmane, norharmane and harmine were also studied and described briefly in the present paper. In the case of harmine, the properties of nitroharmine derivatives $3 \mathbf{a}-\mathbf{c}$ are also compared with that of the chloroharmine derivatives $\mathbf{3 d}-\mathbf{f}$. 


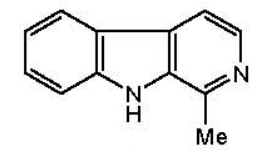

1

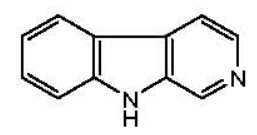

2

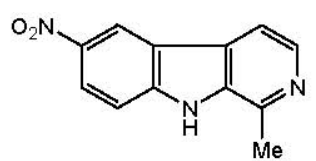

1a

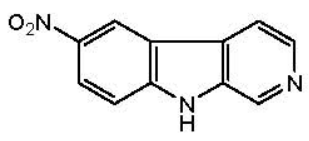

2a

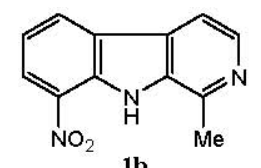

$1 b$

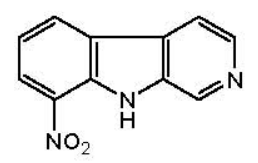

$2 b$
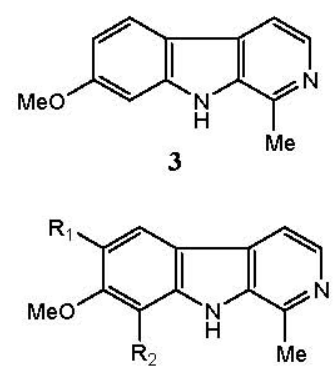

$\begin{array}{llll}\text { 3a } & \mathrm{R}_{1}=\mathrm{NO}_{2} ; \mathrm{R}_{2}=\mathrm{H} & \text { 3d } \mathrm{R}_{1}=\mathrm{Cl} ; \mathrm{R}_{2}=\mathrm{H} \\ \text { 3b } & \mathrm{R}_{1}=\mathrm{H} ; \mathrm{R}_{2}=\mathrm{NO}_{2} & \text { 3e } \mathrm{R}_{1}=\mathrm{H} ; \mathrm{R}_{2}=\mathrm{Cl} \\ \text { 3c } & \mathrm{R}_{1}=\mathrm{NO}_{2} ; \mathrm{R}_{2}=\mathrm{NO}_{2} & \text { 3f } \mathrm{R}_{1}=\mathrm{Cl} ; \mathrm{R}_{2}=\mathrm{Cl}\end{array}$

Scheme 1. $\beta$-Carbolines studied.

\section{Results and Discussion}

It is known, ${ }^{3,4}$ in the absence of photochemical reactions, the fluorescence quantum yield $\varphi_{\mathrm{f}}$ of an emitting substance is given by the ratio of rate constants shown in eq. 1 :

$$
\varphi_{\mathrm{f}=} \mathrm{k}_{\mathrm{f}}^{0} /\left[\mathrm{k}_{\mathrm{f}}^{0}+\mathrm{k}_{\mathrm{isc}}+\mathrm{k}_{\mathrm{ic}}\right]=\mathrm{k}_{\mathrm{f}}^{0} \tau_{\mathrm{f}}=\tau_{\mathrm{f}} / \tau_{\mathrm{f}}^{0} \quad \text { eq. } 1
$$

where the subscripts denote respectively the processes of fluorescence (f), intersystem crossing (isc) and internal conversion (ic). The parameters $\tau_{\mathrm{f}}$ and $\tau_{\mathrm{f}}^{0}$ represent respectively the fluorescence and radiative lifetime. When a spin - orbital mechanism operates due to the presence of chlorine atom or a nitro group attached to the aromatic moiety, the rate constant $\mathrm{k}_{\mathrm{isc}}$ is increased, and hence both $\tau_{\mathrm{f}}$ and $\varphi_{\mathrm{f}}$ are reduced significantly as $\mathrm{k}_{\mathrm{isc}}$ grows larger. Also, the spin - orbital mechanism affects the absorption spectra of nitro aromatic compounds where a strong enhancement of $\varepsilon\left(\mathrm{S}_{0} \rightarrow \mathrm{T}_{1}\right)$ is observed but not on $\varepsilon\left(\mathrm{S}_{0} \rightarrow \mathrm{S}_{1}\right){ }^{3,4}$ Because of the relationship between $\varepsilon\left(\mathrm{S}_{0} \rightarrow \mathrm{T}_{1}\right)$ and $\mathrm{k}_{\mathrm{p}}^{0}$ and between $\varepsilon\left(\mathrm{S}_{0} \rightarrow \mathrm{S}_{1}\right)$ and $\mathrm{k}_{\mathrm{f}}^{0}\left(\mathrm{k}_{\mathrm{f}}^{0}=1 / \tau^{0}\right)$ it is expected that $\mathrm{k}_{\mathrm{p}}^{0}$ but not $\mathrm{k}_{\mathrm{f}}^{0}$ will be influenced by spin - orbital perturbation. Therefore, a study of the fluorescence and phosphorescence spectroscopy, the corresponding $\varphi_{\mathrm{f}}$ and $\varphi_{\mathrm{p}}$ and the comparison of the photophysical rate constants, $\mathrm{k}_{\mathrm{f}}^{0}$ and $\mathrm{k}_{\mathrm{p}}^{0}$, is essential in order to understand the spin orbital mechanism. The much higher values of $\varphi_{\mathrm{p}}$ reflect both a greater efficiency of population of $T_{1}\left(k_{i s c}\right.$ is enhanced $)$ and a greater efficiency of emission from $T_{1}\left(k_{p}^{0}\right.$ is enhanced more than $\mathrm{k}_{\mathrm{st}}$ ).

\section{Absorption Spectroscopy}

The absorption spectra of $\beta$-carbolines were recorded in acetonitrile and in methanol at $298 \mathrm{~K}$ and generally they showed two bands in the 290-330 and 320 -360 nm region (Figure 1a). Previous spectroscopic studies and theoretical calculations have been carried out ${ }^{1 \mathrm{c}-1 \mathrm{e}, 17}$ allowing for unambiguous assignment of the lowest-lying excited electronic states of $\beta$-carbolines as ${ }^{1} \mathrm{~L}_{\mathrm{a}}$ 
and ${ }^{1} \mathrm{~L}_{\mathrm{b}}$ in the $\mathrm{C}_{2 \mathrm{v}}$ symmetry point group with the short (z) axis and long (y) axis respectively in the plane of the molecule. Comparing the position and oscillator strength of the bands located in the 300 and $330 \mathrm{~nm}$ region for chloroharmines with that of harmine, it is possible to assign them as ${ }^{1} \mathrm{~L}_{\mathrm{a}}\left(\mathrm{S}_{2}-\mathrm{S}_{0}\right)$ and ${ }^{1} \mathrm{~L}_{\mathrm{b}}\left(\mathrm{S}_{1}-\mathrm{S}_{0}\right)$ electronic transitions too (Figure 1a).
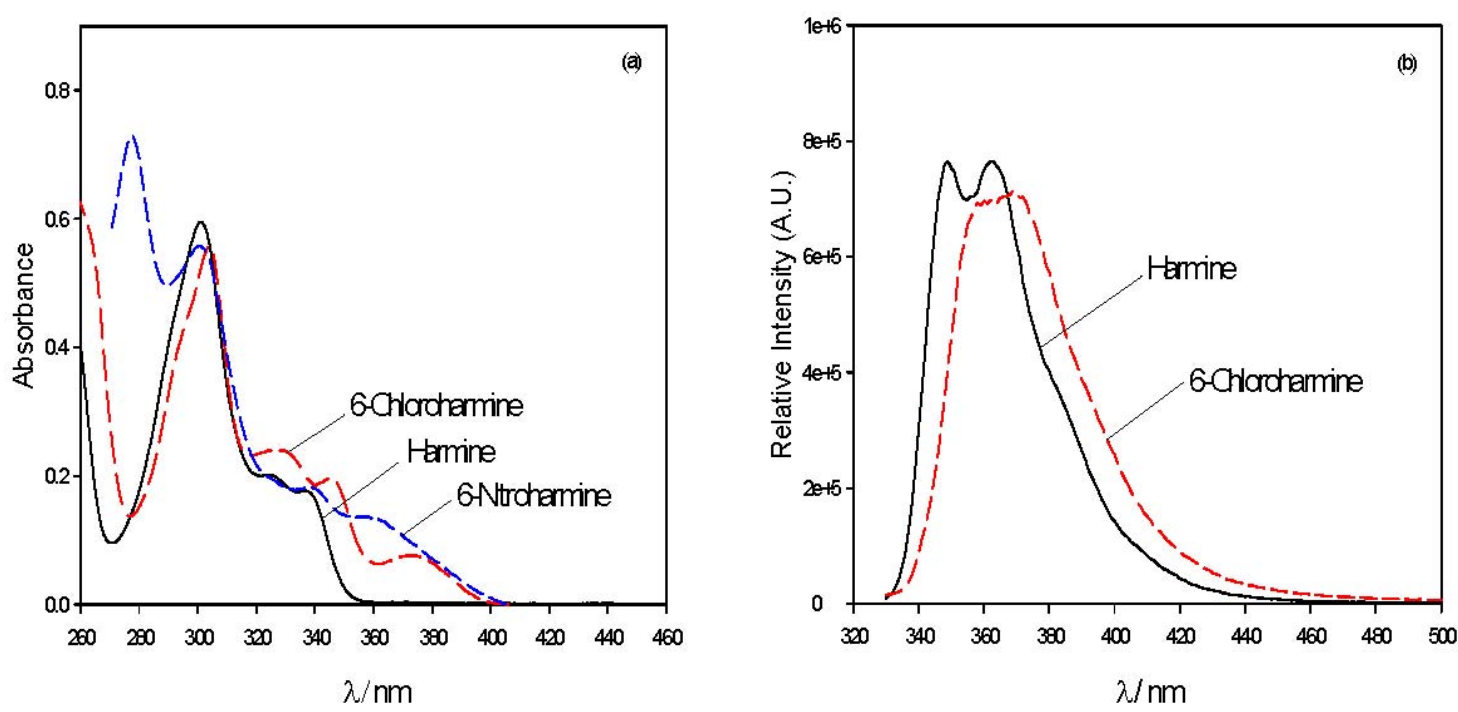

Figure 1. (a) Absorption spectra of harmine, 6-chloroharmine and 6-nitroharmine in acetonitrile (Concentration: $1 \times 10^{-5} \mathrm{~mol} . \mathrm{dm}^{-3}$ ) at room temperature. (b) Fluorescence emission spectra of harmine and 6-chloroharmine in acetonitrile (Concentration: $1 \times 10^{-5} \mathrm{~mol}_{\mathrm{dm}}{ }^{-3} ; \lambda_{\text {exc }}: 310 \mathrm{~nm}$ ) at $298 \mathrm{~K}$.

The absorption spectra of the nitro $\beta$-carboline derivatives recorded in acetonitrile and in methanol at $298 \mathrm{~K}$ exhibit a noticeable bathochromic shift of the ${ }^{1} \mathrm{~L}_{\mathrm{b}}$ band ranging between 20 and $40 \mathrm{~nm}$ compared to that of the $\beta$-carbolines 1-3 (Tables 1 and 2; Fig. 1a). This large red shift accounts for the in-plane conjugation of the nitro substituents and it can be interpreted by the mesomeric effect induced by the nitro group bonded to the $\beta$-carboline moiety (Tables 1 and 2). The absorption spectra of chloroharmines (3d-3f) show a minor bathochromic shift of the ${ }^{1} \mathrm{~L}_{\mathrm{b}}$ band ranging between 4 and $16 \mathrm{~nm}$. This moderated red shift is due to a minor mesomeric effect of the chlorine atom attached to the harmine moiety (Tables 1 and 2). In general, the absorption spectra of chloroharmine and nitro- $\beta$-carbolines show a small bathochromic shift of the ${ }^{1} \mathrm{~L}_{\mathrm{a}}$ electronic transition bands with respect to non-substituted $\beta$-carbolines $\mathbf{1}, \mathbf{2}$ and $\mathbf{3}$ and this moderate red shift ranges from 2 to $6 \mathrm{~nm}$. 
Table 1. Spectroscopic data $\left(\lambda_{\max }(\mathrm{abs})\right.$ and $\left.\lambda_{\max }(\mathrm{em})[\mathrm{nm}]\right)$, fluorescence quantum yield $\left(\varphi_{\mathrm{f}}\right)$ and fluorescence lifetime $\left(\tau_{\mathrm{f}}[\mathrm{ns}]\right)$ of $\beta$-carbolines and substituted $\beta$-carbolines in $\mathrm{MeCN}$ and in $\mathrm{MeCN}+\mathrm{HClO}_{4}$ at $298 \mathrm{~K}$

\begin{tabular}{ccccccccc}
\hline \multirow{2}{*}{ Compd. } & \multicolumn{4}{c}{$\mathrm{MeCN}$} & \multicolumn{5}{c}{$\mathrm{MeCN}+\mathrm{H}^{+}$} \\
\cline { 2 - 9 } & $\lambda_{\max }(\mathrm{abs})$ & $\lambda_{\max }(\mathrm{em})$ & $\varphi_{\mathrm{f}}$ & $\tau_{\mathrm{f}}$ & $\lambda_{\max }(\mathrm{abs})$ & $\lambda_{\max }(\mathrm{em})$ & $\varphi_{\mathrm{f}}$ & $\tau_{\mathrm{f}}$ \\
\hline $\mathbf{1}$ & 344 & 369 & 0.23 & 4.3 & 366 & 433 & 0.75 & 22.4 \\
$\mathbf{1 a}$ & 364 & $N F^{a}$ & - & - & 362 & 446 & 0.005 & - \\
$\mathbf{1 b}$ & 394 & $N F$ & - & - & 384 & 440 & 0.006 & - \\
$\mathbf{2}$ & 346 & 369 & 0.25 & 3.9 & 368 & 434 & 0.72 & 22.0 \\
$\mathbf{2 a}$ & 366 & $N F$ & - & - & 366 & 446 & 0.004 & - \\
$\mathbf{2 b}$ & 396 & $N F$ & - & - & 392 & 442 & 0.006 & - \\
$\mathbf{3}$ & 332 & 362 & 0.39 & 5.1 & 360 & 416 & 0.64 & 7.2 \\
$\mathbf{3 a}$ & 360 & $N F$ & - & - & 356 & 417 & 0.003 & - \\
3b & 372 & $N F$ & - & - & 363 & 425 & 0.003 & - \\
3c & 432 & $N F$ & - & - & 376 & 422 & 0.005 & - \\
3d & 336 & 364 & 0.06 & 2.0 & 360 & 426 & 0.10 & 2.1 \\
3e & 342 & 366 & 0.04 & 1.3 & 364 & 429 & 0.19 & 2.0 \\
3f & 348 & 360 & 0.04 & 1.1 & 358 & 435 & 0.07 & - \\
\hline
\end{tabular}

${ }^{a} N F$ : non fluorescent.

Table 2. Spectroscopic data $\left(\lambda_{\max }(\mathrm{abs})\right.$ and $\left.\lambda_{\max }(\mathrm{em})[\mathrm{nm}]\right)$, fluorescence quantum yield $\left(\varphi_{\mathrm{f}}\right)$ and fluorescence lifetime $\left(\tau_{\mathrm{f}}[\mathrm{ns}]\right)$ of $\beta$-carbolines and substituted $\beta$-carbolines in $\mathrm{MeOH}$ and in $\mathrm{MeOH}+\mathrm{HClO}_{4}$ at $298 \mathrm{~K}$

\begin{tabular}{ccccccccc}
\hline \multirow{2}{*}{ Compd. } & \multicolumn{4}{c}{$\mathrm{MeOH}$} & \multicolumn{5}{c}{$\mathrm{MeOH}+\mathrm{H}+$} \\
\cline { 2 - 9 } & $\lambda_{\max }(\mathrm{abs})$ & $\lambda_{\max }(\mathrm{em})$ & $\varphi_{\mathrm{f}}$ & $\tau_{\mathrm{f}}$ & $\lambda_{\max }(\mathrm{abs})$ & $\lambda_{\max }(\mathrm{em})$ & $\varphi_{\mathrm{f}}$ & $\tau_{\mathrm{f}}$ \\
\hline $\mathbf{1}$ & 350 & 375 & 0.30 & 5.3 & 370 & 430 & 0.70 & 21.2 \\
$\mathbf{1 a}$ & 352 & $N F^{a}$ & - & - & 375 & 432 & 0.09 & - \\
$\mathbf{1 b}$ & 390 & $N F^{a}$ & - & - & 384 & 436 & 0.11 & - \\
$\mathbf{2}$ & 352 & 379 & 0.31 & 6.0 & 376 & 445 & 0.60 & 24.2 \\
$\mathbf{2 a}$ & 342 & $N F^{a}$ & - & - & 364 & $N F$ & - & - \\
2b & 392 & $N F^{a}$ & - & - & 392 & $N F^{a}$ & - & - \\
3 & 338 & 367 & 0.40 & 5.4 & 364 & 415 & 0.45 & 6.8 \\
3a & 342 & $N F^{a}$ & - & - & 360 & $N F$ & - & - \\
3b & 398 & $N F^{a}$ & - & - & 360 & $N F^{a}$ & - & - \\
3d & 342 & 369 & 0.10 & 2.6 & 368 & 420 & 0.10 & 2.0 \\
3e & 348 & 372 & 0.07 & 1.1 & 373 & 427 & 0.05 & 2.0 \\
3f & 352 & 360 & 0.05 & 0.9 & 363 & 430 & 0.04 & 2.5 \\
\hline
\end{tabular}

${ }^{a} N F$ : non fluorescent. 
The absorption spectra of $\beta$-carbolines $(\mathbf{1}-\mathbf{3})$ and chloroharmines $(\mathbf{3 e}-\mathbf{3 f})$ were recorded in $\mathrm{MeOH}$ and in $\mathrm{MeCN}$ doped with $\mathrm{HClO}_{4}$. When the absorption spectra of $\beta$-carbolines and chloroharmines in neutral conditions are compared with those spectra recorded in acidic media a bathochromic shift (around $20 \mathrm{~nm}$ ) is observed for the lowest-lying energy bands (see Tables 1 and 2). The spectral change is attributed to the formation of a cationic species due to an acid-base equilibrium process in the electronic ground state, as shown in Figure 2 for norharmane.

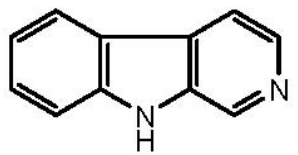

$\lambda_{\max }(\mathrm{abs}): 344 \mathrm{~nm}$
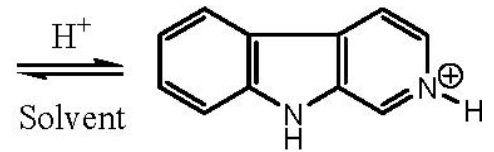

$\lambda_{\max }(\mathrm{abs}): 366 \mathrm{~nm}$

Figure 2. Acid-base equilibrium of norharmane in the electronic ground state.

This behavior could be attributed to the fact that a change of the lowest-lying electronic transition takes place upon protonation of the pyridine nitrogen atom. Therefore, the lowest energy band of the neutral $\beta$-carbolines, which is a $\pi, \pi^{*}$ electronic transition, is red shifted because the HOMO increases its electron density. When protonation takes place the $n$ electron pair at pyridine $\mathrm{N}$ increases its $\sigma$ character and the probability of its interaction (overlapping) with the $\pi$ HOMO is higher. Then, a red shift is expected for the lowest energy band in the absorption spectra. This kind of behavior upon protonation of the $\beta$-carboline moiety was first observed and rationalized by Aullo and Tomas Vert for norharmane, harmane and harmine. ${ }^{17}$

Instead, the comparison of the $\lambda_{\max }(\mathrm{abs})$ data collected in Tables 1 and 2 for the nitro- $\beta$ carbolines and its cationic species shows a minor blue shift of 2 to $10 \mathrm{~nm}$. This behavior is attributed to the fact that an increase of $\Delta \mathrm{E}$ for the lowest-lying electronic transition takes place after protonation of the pyridine nitrogen atom. Therefore, the lowest energy band of the neutral nitro- $\beta$-carbolines has, in some extent, an $n, \pi^{*}$ character. Thus, when protonation occurs, a blue shift is expected for the lowest energy band in the absorption spectra. ${ }^{3,4}$

\section{Emission spectroscopy}

Emission at $298 \mathrm{~K}$. The $\beta$-carbolines 1, 2 and 3 are good fluorescent chromophores with $\varphi_{\mathrm{f}}$ values ranging from 0.20 to 0.40 and $\tau_{\mathrm{f}}$ values of the order of $4-6 \mathrm{~ns}$ (see Tables 1 and 2). ${ }^{1 \mathrm{e}, 18}$ These compounds display mirror symmetry when the fluorescent emission and absorption spectra are compared (spectra of harmine (3) are shown in Figures $1 \mathrm{a}$ and $1 \mathrm{~b}) .{ }^{1 \mathrm{e}}$ The fluorescence lifetimes $\left(\tau_{\mathrm{f}}\right)$ of the corresponding cationic species were measured in $\mathrm{MeCN}$ and in $\mathrm{MeOH}$ doped with $\mathrm{HClO}_{4}$ by the TC-SPC technique; $\tau_{\mathrm{f}}$ values of 22 ns were obtained for compounds 1 and $\mathbf{2}$ while for compound $\mathbf{3}$ the $\tau_{\mathrm{f}}$ value was 7.2 ns (Tables 1 and 2). Pardo et al. ${ }^{18}$ have measured the $\varphi_{\mathrm{f}}$ and $\tau_{\mathrm{f}}$ values of compounds 1, 2 and 3 in ethanol and in acidic media. Comparison of our results measured in methanol with those of Pardo, we can conclude that the $\varphi_{\mathrm{f}}$ values of compounds $\mathbf{1}, \mathbf{2}$ and $\mathbf{3}$ in methanol are similar and show the same trend while the $\tau_{\mathrm{f}}$ 
values of these compounds are higher than those reported by Pardo.

The absorption and fluorescence spectra of chloroharmines $(\mathbf{3 d}-\mathbf{3 f})$ recorded in acetonitrile and in methanol at $298 \mathrm{~K}$ display excellent symmetry as is shown in Figures 1a and 1b. This indicates that the geometries of the molecules are quite similar in their ground and excited states. Tables 1 and 2 show that the $\lambda_{\max }$ (fluo) of mono-chloroharmine derivatives 3d-3e display a minor bathochromic shift ranging from 2 to $6 \mathrm{~nm}$ in comparison to harmine (3). This effect depends on the position and number of the chlorine atoms attached to the harmine moiety. This effect is due to a mild in-plane conjugation of the chlorine atom with the harmine moiety. For the dichloroderivative $\mathbf{3 f}$ a minor hypsochromic shift was observed (Tables 1 and 2). We have also measured the fluorescence quantum yield $\left(\varphi_{f}\right)$ and the fluorescence lifetime $\left(\tau_{f}\right)$ for compounds $\mathbf{3}$, 3d - 3f in $\mathrm{MeCN}$ and in $\mathrm{MeOH}$ (see Tables 1 and 2). As it was expected the intramolecular quenching of the fluorescence emission (intramolecular heavy atom effect, HAE) of chloro- $\beta$ carbolines $\mathbf{3 d}-\mathbf{3 f}$ increases as the number of chlorine atoms attached to the $\beta$-carboline moiety is increased. This trend is evidenced through the $\varphi_{\mathrm{f}}$ values of compounds $\mathbf{3 d}-\mathbf{3 f}$ that decrease an $80-90 \%$ relative to the $\varphi_{\mathrm{f}}$ value of harmine (3). A similar trend is observed when the $\tau_{\mathrm{f}}$ values are analyzed (Tables 1 and 2).

As it is expected, the nitro- $\beta$-carbolines are not fluorescent chromophores in $\mathrm{MeCN}$ and in $\mathrm{MeOH}$ due to the nitro group attached to the $\beta$-carboline moiety where a high spin - orbital coupling mechanism operates. This behavior means that these molecules dissipate efficiently the energy from $\mathrm{S}_{1}$ through radiationless processes (internal conversion and/or intersystem crossing processes).

The emission fluorescence spectra of $\beta$-carbolines 1-3, chloro- and nitro- $\beta$-carbolines were recorded in $\mathrm{MeCN}$ doped with $\mathrm{HClO}_{4}$, showing a broad band centered between 416 and $446 \mathrm{~nm}$ depending on the substituent attached to the $\beta$-carboline moiety (Table 1 ). When the solvent used was $\mathrm{MeOH}$ doped with acid, a similar behavior was observed for the $\beta$-carbolines except for compounds 2a, 2b, 3a and 3b, where no fluorescence emission was detected (Table 2). The comparative analysis of the $\varphi_{\mathrm{f}}$ values in acetonitrile acidic conditions show that the cationic species of harmane, norharmane and harmine are excellent fluorophores $\left(\varphi_{\mathrm{f}} 0.75,0.72\right.$ and 0.64$)$. It is noteworthy to point out that the cationic species of chloro- and nitro- $\beta$-carboline derivatives show a fluorescence emission quantum yield that diminishes in a significant extent due to a high spin-orbital coupling mechanism ((intramolecular fluorescence quenching; see Table 1). This trend is clearly depicted if the $\varphi_{\mathrm{f}}$ values are compared: $\mathbf{3}, \varphi_{\mathrm{f}}=0.64 ; \mathbf{3 d}, \varphi_{\mathrm{f}}=0.10 ; \mathbf{3 b}, \varphi_{\mathrm{f}}=0.003$. Also, the $\tau_{\mathrm{f}}$ values for compounds $\mathbf{3}, \mathbf{3 d}$ and $\mathbf{3 e}$ show a decreasing trend due to the HAE of chlorine atoms attached to the harmine moiety. The $\varphi_{\mathrm{f}}$ and $\tau_{\mathrm{f}}$ values in methanolic acidic conditions show a similar trend for the $\beta$-carboline derivatives analyzed except for compounds $\mathbf{2 a}, \mathbf{2 b}, \mathbf{3} \mathbf{a}$ and $\mathbf{3 b}$, where no fluorescence emission was detected.

\section{Emission at $77 \mathrm{~K}$}

We have measured the fluorescence and phosphorescence emission spectra and the spectroscopic parameters $\left(\varphi_{\mathrm{f}}, \varphi_{\mathrm{p}}\right.$ and $\left.\tau_{\mathrm{p}}\right)$ of compounds $\mathbf{1}, \mathbf{2}, \mathbf{3}, \mathbf{1 a}, \mathbf{1 b}, \mathbf{2 a}, \mathbf{2 b}$, and $\mathbf{3 a - 3 f}$ in solid matrix at $77 \mathrm{~K}$ 
and the data are collected in Table 3 ((a) isopropanol-ethyl ether (1:1)). Compounds $\mathbf{1}, 2$ and 3 are good fluorescent and phosphorescent chromophores at $77 \mathrm{~K}$ showing the $\lambda_{\max }$ (fluo) at 360 $\mathrm{nm}$ and the $\lambda_{\max }$ (phosph) around $410 \mathrm{~nm}$. The $\varphi_{\mathrm{f}}$ values of these compounds are high, ranging between 0.67 and 0.91 . These compounds deactivate their excited triplet state through a moderate phosphorescence emission $\left(\varphi_{\mathrm{p}}: 0.36\right)$ and a radiationless pathway competes in the deactivation of the excited triplet state in a great extent. Taking into account that the shape of the phosphorescence emission spectra is "naphthalene-like" and the phosphorescence lifetimes $\left(\tau_{\mathrm{p}}\right)$ are on the time scale of seconds we concluded that the electronic excited triplet state is most likely to be a $\pi, \pi^{*}$ electronic transition. ${ }^{3}$

The nitroderivatives 1a, 1b and 3a-c do not show emission in solid matrix at $77 \mathrm{~K}$. Thus, the triplet excited states deactivate efficiently through a radiationless pathway. Instead, nitronorharmane derivatives (2a and $\mathbf{2} \mathbf{b}$ ) show $\varphi_{p}$ values lesser than that of harmane (2) indicating that these compounds deactivate efficiently the excited triplet state through a radiationless process while the radiative deactivation takes place to a lesser extent. In the case of nitronorharmane derivatives (2a and $\mathbf{2 b}$ ) the shape of the phosphorescence emission spectra are "benzophenone-like"; due to the presence of the nitro group attached to the $\beta$-carboline moiety it resembles the phosphorescence emission spectra of benzophenone.

Comparison of the $\lambda_{\max }$ (phosph) values of the nitro-harmane derivatives with that of harmane a bathochromic shift is observed due to the in-plane conjugation of the nitro group with the $\beta$ carboline moiety (Table 3 (a)).

It is interesting to note that compounds $\mathbf{3 d}$ and $\mathbf{3 e}$ show fluorescence and phosphorescence emissions in solid matrix at $77 \mathrm{~K}$ and again, the spin - orbital coupling mechanism operates because the $\varphi_{\mathrm{f}}$ values diminish significantly in comparison with $\varphi_{\mathrm{f}}$ value of harmine (see Table 3 (a)). In this connection, it is expected that an enhancement of the intersystem crossing process from $\mathrm{S}_{1}$ to $\mathrm{T}_{1}$ for compounds $\mathbf{3 d}$ and $\mathbf{3 e}$ takes place; this process is thermodynamically favored as can be seen from the values of $\Delta \mathrm{E}\left(\mathrm{T}_{1}-\mathrm{S}_{1}\right)$ shown in Table 3 . A bathochromic shift $(25 \mathrm{~nm})$ of the $\lambda_{\max }(\mathrm{phosph})$ is observed for 6-chloro- and 8-chloroharmine which is due to the in-plane conjugation of chlorine atom with the harmine moiety. The chloro- $\beta$-carboline derivatives show $\varphi_{p}$ values higher than that of harmine indicating that these compounds deactivate efficiently the excited triplet state through phosphorescence radiation. Taking into account the $\tau_{\mathrm{p}}$ values and the shape of the electronic phosphorescence emission spectra we concluded that the electronic excited triplet state is mostly $\pi, \pi^{*}$ for compounds $\mathbf{3 d}$ and $\mathbf{3 e}$. The dichloroharmine derivative $\mathbf{3 f}$ does not show emission in solid matrix at $77 \mathrm{~K}$.

We have also studied the fluorescence and phosphorescence emission spectra of the cationic species of 1, 2, 3, 1a, 1b, 2a, 2b, and 3a-3f in solid matrix at $77 \mathrm{~K}$ (Table 3; (b) isopropanolethyl ether (1:1) doped with $\left.\mathrm{HClO}_{4}\right)$. In general, the cationic species show a significant phosphorescence emission as a broad band centered between 445 to $483 \mathrm{~nm}$ depending on the compound studied. 
Table 3. Spectroscopic data $\left(\lambda_{\max }(\right.$ fluo $)$ and $\lambda_{\max }($ phosph) $[\mathrm{nm}])$, fluorescence quantum yield $\left(\varphi_{\mathrm{f}}\right)$, phosphorescence quantum yield $\left(\varphi_{\mathrm{p}}\right)$ and phosphorescence lifetime $\left(\tau_{\mathrm{p}}[\mathrm{s}]\right)$ of $\beta$-carbolines and $\beta$ carboline derivatives in solid matrix at $77 \mathrm{~K}$

(a) Isopropanol-ethyl ether $(1: 1)$

\begin{tabular}{cccccc}
\hline Compound & $\lambda_{\max }($ fluo $)$ & $\lambda_{\max }($ phosph $)$ & $\Delta \mathrm{E}\left(\mathrm{T}_{1}-\mathrm{S}_{1}\right)^{\mathrm{a}}$ & $\varphi_{\mathrm{f}}$ & $\varphi_{\mathrm{p}}{ }^{\mathrm{b}}$ \\
\hline $\mathbf{1}$ & 357 & 419 & -0.57 & 0.84 & 0.36 \\
$\mathbf{2}$ & 360 & 419 & -0.56 & 0.67 & 0.36 \\
$\mathbf{2 a}$ & - & 435 & - & - & 0.10 \\
$\mathbf{2 b}$ & - & 436 & - & - & 0.18 \\
$\mathbf{3}$ & 361 & 405 & -0.61 & 0.91 & 0.37 \\
3d & 363 & 430 & -0.75 & 0.60 & 0.53 \\
3e & 369 & 425 & -0.64 & 0.28 & 0.73 \\
\hline
\end{tabular}

(b) Isopropanol-ethyl ether (1:1) doped with $\mathrm{HClO}_{4}$ before freezing

\begin{tabular}{ccccc}
\hline Compound & $\lambda_{\max }($ fluo $)$ & $\lambda_{\max }($ phosph $)$ & $\varphi_{\mathrm{f}}$ & $\varphi_{\mathrm{p}}{ }^{\mathrm{c}}$ \\
\hline $\mathbf{1}$ & - & 477 & - & 0.63 \\
$\mathbf{1 a}$ & - & 475 & - & 0.24 \\
$\mathbf{1 b}$ & - & 475 & - & 0.31 \\
$\mathbf{2}$ & - & 477 & - & 0.62 \\
$\mathbf{2 a}$ & - & 477 & - & 0.20 \\
$\mathbf{2 b}$ & - & 477 & - & 0.50 \\
$\mathbf{3}$ & - & 460 & - & 0.56 \\
3a & - & 455 & - & 0.72 \\
3b & - & 445 & - & 0.58 \\
3c & - & 430 & - & 0.16 \\
3d & - & 483 & - & 0.33 \\
3e & - & 472 & - & 0.17 \\
\hline
\end{tabular}

${ }^{\mathrm{a}}$ Values calculated in eV. ${ }^{\mathrm{b}} \tau_{\mathrm{p}}: \mathbf{1}, 4.8 ; \mathbf{2}, 4.6 ; \mathbf{3}, 2.5 ; \mathbf{3 d}, 0.38 ; \mathbf{3 e}, 0.55 .{ }^{\mathrm{c}} \tau_{\mathrm{p}}: \mathbf{1}+\mathbf{H}^{+}, 5.7 ; \mathbf{2}+\mathbf{H}^{+}, 4.4$; $\mathbf{3}+\mathbf{H}^{+}, 3.1 ; \mathbf{3} \mathbf{d}+\mathbf{H}^{+} 0.84 ; \mathbf{3 e}+\mathbf{H}^{+}, 0.61$.

The cationic species of compounds $\mathbf{1}, \mathbf{2}$ and $\mathbf{3}$ have high $\varphi_{p}$ values and this indicates that the phosphorescence emission is the efficient deactivation pathway of the excited triplet state. Instead, for the cationic species of the chloro-derivatives $\mathbf{3 d}$ and $\mathbf{3 e}$ a radiationless pathway deactivates the excited triplet states and competes efficiently with the phosphorescence emission. From the $\tau_{\mathrm{p}}$ values for cationic species of $\mathbf{1}, \mathbf{2}, \mathbf{3}, \mathbf{3 d}$ and $\mathbf{3 e}$ we concluded again that the excited 
triplet states are most likely to be $\pi, \pi^{*}$. The dichloroharmine derivative $\mathbf{3 f}$ does not show emission in solid acidic matrix at $77 \mathrm{~K}$ (Table 3 (b)).

In acidic conditions, the $\varphi_{p}$ values of the cationic species of the nitro- $\beta$-carbolines $1 \mathbf{a}, \mathbf{1} \mathbf{b}, \mathbf{2 a}$ and $\mathbf{2 b}$ are smaller than that of cationic species of compounds $\mathbf{1}$ and $\mathbf{2}$. Instead, for the cationic species of compounds $\mathbf{3} \mathbf{a}$ and $\mathbf{3} \mathbf{b}$ the $\varphi_{p}$ values are quite similar to that of the cationic harmine. We concluded that these compounds deactivate the excited triplet state through a radiative (phosphorescence emission) process as efficiently as cationic harmine (3) do, in competition with the radiationless process.

Recently, Varela et al. ${ }^{19}$ described the phosphorescence spectra, $\varphi_{\mathrm{p}}$ and $\tau_{\mathrm{p}}$ at $77 \mathrm{~K}$ for the neutral and cationic forms of compounds 1, 2 and 3. The values obtained and the conclusions reached are similar to those discussed above.

\section{Photophysical parameters and triplet transient absorption spectroscopy}

In order to calculate the different rate constants of the deactivation of the lowest singlet excited state $\left(k_{\mathrm{f}}^{0}, k_{\mathrm{ic}}\right.$ and $\left.k_{\mathrm{isc}}\right)$ of $\beta$-carbolines $\mathbf{1 ,} \mathbf{2}$ and $\mathbf{3}$ and chloroharmines $\mathbf{3 d}, \mathbf{3 e}$ and $\mathbf{3 f}$ we measured the $\varphi_{\text {isc }}$ of these compounds in acetonitrile and methanol by Laser Flash Photolysis at room temperature and the $\varphi_{\text {isc }}$ values are collected in Table 4 . These values were measured following the absorbance of the triplet transient of 1-cyanonaphthalene (triplet energy acceptor) formed at $500 \mathrm{~nm}$ after excitation with a laser pulse at $\lambda=355 \mathrm{~nm}$ in the presence of benzophenone, which was chosen as a reference $\left(\varphi_{\text {isc }}=1\right)$, and in the presence of the $\beta$-carboline derivatives. 1Cyanonaphthalene was chosen as a triplet energy acceptor because the triplet energy is located at $57 \mathrm{Kcal} / \mathrm{mol}^{20}$ and the energy of the triplet excited states of benzophenone and $\beta$-carboline derivatives are higher than $65 \mathrm{Kcal} / \mathrm{mol}$. Therefore, the triplet energy transfer process from the triplet excited state of the substrates (and reference) to the triplet excited state of the energy acceptor (1-cyanonaphthalene) is thermodynamically feasible.

In the absence of photochemical reaction, it is known that equation 2 is valid for any organic chromophore, in particular, $\beta$-carboline derivatives:

$$
1=\varphi_{\mathrm{f}}+\varphi_{\mathrm{isc}}+\varphi_{\mathrm{ic}} \quad \text { eq. } 2
$$

Taking into account that the quantum yield of fluorescence $\left(\varphi_{f}\right)$ and the quantum yield of intersystem crossing $\left(\varphi_{\text {isc }}\right)$ were measured independently by different spectroscopic methods in methanol and in acetonitrile at $298 \mathrm{~K}$, the $\varphi_{\text {ic }}$ values are easily derived from equation 2 and these data are shown in Table 4. In this connection, we are now able to calculate the radiative and radiationless deactivation rate constants of the lowest singlet excited states $\left(k_{\mathrm{f}}^{\mathrm{o}}, k_{\mathrm{isc}}\right.$ and $\left.k_{\mathrm{ic}}\right)$ of $\beta$ carbolines 1, 2 and $\mathbf{3}$ and chloroharmines $\mathbf{3 d}$, 3e and $\mathbf{3 f}$ using eq. 1 and the relationships: $\varphi_{\text {isc }}=$ $k_{\text {isc }} . \tau_{\mathrm{f}}$ and $\varphi_{\text {ic }}=k_{\text {ic }} . \tau_{\mathrm{f}}$. These data are collected in Table 4.

From the analysis of the $k_{\mathrm{f}}^{\mathrm{o}}, k_{\text {isc }}$ and $k_{\text {ic }}$ values, we can conclude that the lowest singlet excited state of $\beta$-carbolines $\mathbf{1}, \mathbf{2}$ and $\mathbf{3}$ is efficiently deactivated through the fast inherent fluorescence emission process $\left(k_{\mathrm{f}}^{\mathrm{o}}\right)$ in competition with the intersystem crossing channel $\left(k_{\text {isc }}\right)$ 
which is highly favored, owing to the high rigidity and planarity of the $\beta$-carboline structures. ${ }^{21}$ Also, the internal conversion process $\left(k_{\mathrm{ic}}\right)$ competes in the deactivation of the lowest singlet excited state of compounds $\mathbf{1}, \mathbf{2}$ and $\mathbf{3}$ in a lesser extent.

The $k_{\text {isc }}$ values of compounds $\mathbf{3}, \mathbf{3 d}, \mathbf{3 e}$ and $\mathbf{3 f}$ show that the intersystem crossing process is an efficient deactivation pathway of the lowest singlet excited state of these compounds and is enhanced as the number of chlorine atoms attached to the $\beta$-carboline moiety is increased. This behavior can be rationalized due to a large HAE effect of the chlorine atoms. Also, the $k_{\mathrm{ic}}$ value of compounds $\mathbf{3}, \mathbf{3 d}, \mathbf{3 e}$ and $\mathbf{3 f}$ increase slightly from harmine to chloroharmine derivatives and this is another competitive radiationless process that deactivates the lowest singlet excited state of these compounds in a lesser extent.

Table 4. Photophysical parameters ( $\varphi_{\mathrm{isc}}, \varphi_{\mathrm{ic}}, \tau_{\mathrm{T}}[\mathrm{ns}], k_{\mathrm{f}}^{\mathrm{o}}\left[\mathrm{s}^{-1}\right], k_{\mathrm{isc}}\left[\mathrm{s}^{-1}\right]$ and $\left.k_{\mathrm{ic}}\left[\mathrm{s}^{-1}\right]\right)$ of $\beta$-carbolines 1-3 and chloroharmines 3d-3f at $298 \mathrm{~K}$

(i) $\mathrm{MeCN}$

\begin{tabular}{ccccccc}
\hline Compound & $\varphi_{\mathrm{isc}}{ }^{\mathrm{a}}$ & $\varphi_{\mathrm{ic}}{ }^{\mathrm{b}}$ & $\tau_{\mathrm{T}}$ & $k_{\mathrm{f}}^{\mathrm{o}}$ & $k_{\mathrm{isc}}$ & $k_{\mathrm{ic}}$ \\
\hline $\mathbf{1}$ & 0.47 & 0.30 & 471 & $5.3 \times 10^{7}$ & $9.1 \times 10^{7}$ & $4.2 \times 10^{7}$ \\
$\mathbf{2}$ & 0.54 & 0.21 & 877 & $6.4 \times 10^{7}$ & $1.3 \times 10^{7}$ & $1.5 \times 10^{7}$ \\
$\mathbf{3}$ & 0.50 & 0.11 & 173 & $7.6 \times 10^{7}$ & $9.8 \times 10^{7}$ & $2.2 \times 10^{7}$ \\
$\mathbf{3 d}$ & 0.53 & 0.41 & - & $3.0 \times 10^{7}$ & $2.7 \times 10^{8}$ & $2.1 \times 10^{8}$ \\
$\mathbf{3 e}$ & 0.55 & 0.41 & - & $3.3 \times 10^{7}$ & $4.2 \times 10^{8}$ & $3.2 \times 10^{8}$ \\
$\mathbf{3 f}$ & 0.50 & 0.43 & - & $6.0 \times 10^{7}$ & $4.5 \times 10^{8}$ & $3.9 \times 10^{8}$ \\
\hline
\end{tabular}

${ }^{a}$ Measured by Laser Flash Photolysis at room temperature. ${ }^{b} \varphi_{\text {ic }}=1-\varphi_{\mathrm{f}}-\varphi_{\text {isc }}$

(ii) $\mathrm{MeOH}$

\begin{tabular}{ccccccc}
\hline Compound & $\varphi_{\mathrm{isc}}{ }^{\mathrm{a}}$ & $\varphi_{\mathrm{ic}}{ }^{\mathrm{b}}$ & $\tau_{\mathrm{T}}$ & $k_{\mathrm{f}}^{\mathrm{o}}$ & $k_{\mathrm{isc}}$ & $k_{\mathrm{ic}}$ \\
\hline $\mathbf{1}$ & 0.48 & 0.22 & 556 & $5.7 \times 10^{7}$ & $1.1 \times 10^{8}$ & $5.1 \times 10^{7}$ \\
$\mathbf{2}$ & 0.57 & 0.21 & 250 & $4.2 \times 10^{7}$ & $1.5 \times 10^{8}$ & $5.4 \times 10^{7}$ \\
$\mathbf{3}$ & 0.49 & 0.04 & 113 & $8.9 \times 10^{7}$ & $9.6 \times 10^{7}$ & $7.8 \times 10^{6}$ \\
$\mathbf{3 d}$ & 0.54 & 0.36 & - & $3.0 \times 10^{7}$ & $2.1 \times 10^{8}$ & $1.4 \times 10^{8}$ \\
$\mathbf{3 e}$ & 0.56 & 0.37 & - & $3.3 \times 10^{7}$ & $5.1 \times 10^{8}$ & $3.4 \times 10^{8}$ \\
$\mathbf{3 f}$ & 0.52 & 0.34 & - & $6.0 \times 10^{7}$ & $5.8 \times 10^{8}$ & $3.8 \times 10^{8}$ \\
\hline
\end{tabular}

${ }^{a}$ Measured by Laser Flash Photolysis at room temperature. ${ }^{b} \varphi_{\text {ic }}=1-\varphi_{\mathrm{f}}-\varphi_{\text {isc }}$

We have also measured the photophysical parameters $\left(\varphi_{\text {isc }}\right.$ and $\left.\tau_{\mathrm{T}}\right)$ and the electronic 
absorption spectra of the triplet transients of the nitro- $\beta$-carbolines in acetonitrile and in methanol at room temperature by Laser Flash Photolysis. Taking into account that the nitro- $\beta$ carbolines do not show any fluorescence emission at room temperature and are photostables upon irradiation, the $\varphi_{\mathrm{ic}}$ value can be easily derived according to the following relationship: $\varphi_{\mathrm{ic}}=$ 1- $\varphi_{\text {isc. }}$ Therefore, the measured spectroscopic and photophysical data and the derived internal conversion quantum yield values $\left(\varphi_{\mathrm{ic}}\right)$ are collected in Table 5.

Table 5. Spectroscopic data $\left(\lambda_{\max }(\mathrm{abs})[\mathrm{nm}]\right)$, intersystem crossing quantum yield ( $\left.\varphi_{\text {isc }}\right)$, internal conversion quantum yield $\left(\varphi_{\mathrm{ic}}\right)$ and triplet lifetime $\left(\tau_{\mathrm{T}}[\mathrm{ns}]\right)$ of nitro- $\beta$-carbolines in acetonitrile and in methanol by Laser Flash Photolysis at $298 \mathrm{~K}$

\begin{tabular}{cccccccccc}
\hline & \multicolumn{4}{c}{$\mathrm{MeCN}$} & \multicolumn{4}{c}{$\mathrm{MeOH}$} \\
\cline { 2 - 10 } Compd. & $\varphi_{\text {isc }}$ & $\varphi_{\mathrm{ic}}{ }^{\mathrm{a}}$ & $\tau_{\mathrm{T}}$ & $\lambda_{\max }(\mathrm{abs})$ & $\varphi_{\text {isc }}$ & $\varphi_{\text {ic }}$ & $\tau_{\mathrm{T}}$ & $\lambda_{\max }(\mathrm{abs})$ \\
\hline 1a & 0.66 & 0.34 & 365 & 525 & 0.53 & 0.47 & 370 & 530 \\
1b & 0.27 & 0.73 & 137 & 500 & 0.43 & 0.57 & 135 & 505 \\
2a & 0.55 & 0.45 & 520 & 515 & 0.58 & 0.22 & 520 & 515 \\
2b & 0.37 & 0.63 & 150 & 520 & 0.45 & 0.55 & 145 & 520 \\
3a & 0.41 & 0.59 & - & - & 0.27 & 0.73 & - & - \\
3b & 0.39 & 0.61 & - & - & 0.39 & 0.61 & - & - \\
3c & 0.10 & 0.90 & - & - & 0.11 & 0.89 & - & - \\
\hline
\end{tabular}

${ }^{\mathrm{a}} \varphi_{\text {ic }}=1-\varphi_{\text {isc }}$

The analyses of the $\varphi_{\text {isc }}$ and $\varphi_{\text {ic }}$ values of nitro- $\beta$-carboline derivatives allow us to conclude that the lowest singlet excited state of these compounds (not experimentally detected), which have a fleeting lifetime ( $\tau_{\mathrm{f}}$ lesser than $1 \mathrm{~ns}$ ), is efficiently deactivated through both radiationless processes: the intersystem crossing (isc) and internal conversion (ic) channels. It is noteworthy to point out that the $\varphi_{\text {isc }}$ values of 6-nitro- $\beta$-carbolines are higher than that of the 8-nitro- $\beta$-carboline regioisomers. This fact could be rationalized taking into account that 8 -nitro- $\beta$-carboline forms an intramolecular hydrogen bond whereas the 6-nitro regioisomer does not, as is depicted in figure 3 .

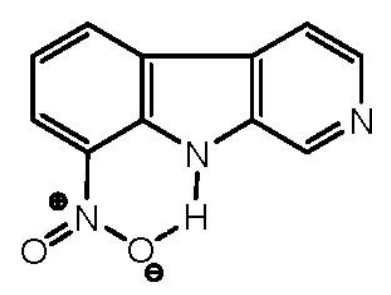

Figure 3. Intramolecular hydrogen bond in 8-nitro-norharmane (2b). 
Therefore, the nitro group is forced to be in-plane with the $\beta$-carboline moiety and the enhancement of the rigidity of the molecule favored the radiationless deactivation of the lowest singlet excited state through the internal conversion channel in competition with the intersystem crossing channel. Of course, this behavior is not possible for 6 -nitro- $\beta$-carbolines and hence, the trend observed is opposite to that of the 8-nitro regioisomers. The analysis of the triplet transient lifetimes of the nitro- $\beta$-carbolines shows a similar trend when the 6-nitro- and 8-nitro- $\beta$ carboline derivatives are compared. Finally, the electronic absorption triplet transient spectra of the nitro- $\beta$-carbolines were recorded by Laser Flash Photolysis at room temperature and showed a broad band from 420 to $600 \mathrm{~nm}$ with a $\lambda_{\max }(\mathrm{abs})$ centered around $500 \mathrm{~nm}$. Similar results were obtained in methanol solution (Table 5).

\section{Conclusions}

In the present study, the radiative and radiationless rate constants $\left(k_{\mathrm{f}}^{\mathrm{o}}, k_{\mathrm{isc}}\right.$ and $\left.k_{\mathrm{ic}}\right)$ of harmane (1), norharmane (2), harmine (3) and chloroharmines $(\mathbf{3 d}-\mathbf{3 f})$ in acetonitrile and in methanol at room temperature were derived from the photophysical parameters: $\tau_{\mathrm{f}}, \varphi_{\mathrm{f}}, \varphi_{\text {isc }}$ and $\varphi_{\mathrm{ic}}$. Also, the $\Delta \mathrm{E}\left(\mathrm{T}_{1}-\mathrm{S}_{1}\right)$ values and the $\varphi_{\mathrm{f}}$ and $\varphi_{\mathrm{p}}$ values were measured in solid matrix at $77 \mathrm{~K}$. An important heavy atom effect for compounds $\mathbf{3 d}-\mathbf{3 f}$ on the photophysical and spectroscopic data was observed in comparison to harmine. Therefore, a noticeable intramolecular quenching of the fluorescence emission spectra at room temperature was observed due to the chlorine atoms attached to the harmine moiety and the $\tau_{\mathrm{f}}$ and $\varphi_{\mathrm{f}}$ parameters decrease while the $k_{\text {isc }}$ parameter increases proportionately. Measurements at $77 \mathrm{~K}$ showed that these compounds are still fluorescent chromophores while an important phosphorescence emission was observed too. A comparative analysis of the photophysical rate constants and the shape of the fluorescence and phosphorescence emission spectra of $\beta$-carbolines and chloroharmines allow us to conclude that the lowest singlet and triplet excited states of compounds $\mathbf{1}, \mathbf{2}, \mathbf{3}$ and $\mathbf{3 d}-\mathbf{3 f}$ are to be $\pi, \pi^{*}$ electronic states.

Nitro- $\beta$-carbolines are not fluorescent chromophores and the fleeting lowest singlet excited state $\left(n, \pi^{*}\right)$ deactivates efficiently through the intersystem crossing and internal conversion pathways. The former pathway operates preferentially for 6-nitro- $\beta$-carbolines while the latter is observed when 8 -nitro- $\beta$-carbolines are studied. In general, the nitro- $\beta$-carboline derivatives show triplet transient absorption spectra between 420 and $600 \mathrm{~nm}$ with a $\lambda_{\max }(\mathrm{abs})$ centered around $500 \mathrm{~nm}$ and the $\tau_{\mathrm{T}}$ values ranged between 135 and $520 \mathrm{~ns}$ depending on the position of the nitro group attached to the $\beta$-carboline moiety. Taking into account that the nitro- $\beta$ carbolines show $\varphi_{\text {ic }}$ values higher than the corresponding $\beta$-carbolines, laser induced optoacoustic spectroscopy (LIOAS) of nitro- $\beta$-carbolines in homogeneous media at $298 \mathrm{~K}$ are in progress in our laboratory in order to analyze the thermal deactivation of the electronic excited states.

$\beta$-Carbolines and nitro- $\beta$-carbolines constitute two families of $9 \mathrm{H}$-pyrido[3,4-b]indole 
compounds, both photostable showing a quite different deactivation process from the electronic excited state.

As the competition between radiative and radiationless deactivation processes of the electronic excited state of the UV-MALDI matrix may strongly affect the efficiency of the desorption/ionization of the analyte in UV-MALDI-MS experiments, ${ }^{2}$ comparative studies using $\beta$-carbolines and nitro- $\beta$-carbolines as matrices are in progress in our laboratory.

\section{Experimental Section}

\section{General Procedures}

Materials. Harmane (1), norharmane (2) and harmine (3) were purchased from Aldrich Chemical Co. Benzophenone and 9-cyanonaphthalene of high quality were purchased from Aldrich Chemical Co. and were used without further purification. Acetonitrile, methanol, ethyl ether and iso-propanol HPLC grade (Merck) were used as purchased without any further purification. Water of MilliQ grade, perchloric acid and sulfuric acid of analytical grade were used. Quinine sulfate and $p$-terphenyl were used as purchased from Aldrich Chemical Co. and Sigma. The chloro- $\beta$-carbolines and the nitro- $\beta$-carbolines were synthesized according to the procedures reported elsewhere. $^{22}$

Equipment. The absorption measurements were performed with a spectrophotometer Hewlett Packard HP5. The spectrofluorometer employed in this study was a Hitachi F-500. The quantum yields at room temperature were determined relatively to the quantum yield of Quinine sulfate in $\mathrm{HClO} 0.1 \mathrm{~N}(\mathrm{QS})$. The general method followed for the measurements has been previously described. ${ }^{23}$

The fluorescence lifetimes were measured by the time correlated single photon counting technique with an Edinburgh 0B 900 nanosecond fluorescence spectrometer. The resulting decay curves were analyzed by deconvoluting a single exponential with the Lamp function as it was described elsewhere. Total luminescence emission spectra (fluorescence and/or phosphorescence) were measured in the same spectrophotometer at $77 \mathrm{~K}$. The conventional flash apparatus was used in order to measure the phosphorescence lifetimes. The fluorescence quantum yields at $298 \mathrm{~K}$ and at $77 \mathrm{~K}$ and the phosphorescence quantum yields at $77 \mathrm{~K}$ were determined according to the procedure previously described in detail. ${ }^{2323}$

Laser flash photolysis experiments were performed by using a pulsed frequency quadrupled Nd:YAG laser (J. K. Lasers HY750, $15 \mathrm{~ns}$ FWHM, maximum energy $75 \mathrm{~mJ}$ at $1.06 \mu \mathrm{m}$ ). The energy of a single $355 \mathrm{~nm}$ pulse was monitored with a beam splitter and a pyroelectric energy meter (Laser Precision Corp.). Laser induced transient transmission changes were monitored, perpendicular to the laser beam, by using a Xe arc lamp (ILC UV 33P). The analysing light passed through a $2 \mathrm{~mm}$ wide section of the excited sample and was then focused at the entrance slit of a $0.25 \mathrm{~m}$, double grating monochromator (PTI f/4, spectral resolution $3 \mathrm{~nm}$ ). A photomultiplier (Hamamatsu R936) and a Tektronix R-7912 transient digitizer interfaced to a PC 
IBM Asyst. Programs were used to acquire and process the signals. The intersystem crossing quantum yields at room temperature were determined relatively to the quantum yield of benzophenone using 1-cyanonaphthalene as a triplet energy acceptor. The triplet lifetimes $\left(\tau_{\mathrm{T}}\right)$ were measured at the maximum wavelength of the electronic absorption spectra of the triplet transients.

\section{Acknowledgements}

The authors thank Universidad de Buenos Aires (X022), CONICET (PIP 5443) and ANPCyT 2002 ( $\mathrm{N}^{\mathrm{O}}$ 12312) for partial financial support and Dr. F. Quina (Federal University of Sao Paulo, Brasil) for the use of the Edimburgh OB900 fluorometer, the laser flash photolysis apparatus and for his generous hospitality. R. Erra-Balsells and S. M. Bonesi are research members and F. M. Cabrerizo is post-doctoral research fellow of CONICET.

\section{Referneces}

1. (a) Erra-Balsells, R.; Frasca, A. R. Tetrahedron 1983, 39, 33. (b) Biondic, M. C.; ErraBalsells, J. Photochem. Photobiol., A: Chem. 1990, 51, 341. (c) Biondic, M.C.; ErraBalsells, R. J. Chem. Soc., Perkin Trans. 2 1992, 1049; (d) Biondic, M. C.; Erra-Balsells, R. J. Chem. Soc., Perkin Trans. 2 1993, 887. (e) Biondic, M. C.; Erra-Balsells, R. J. Photochem. Photobiol., A: Chem. 1994, 77, 149. (f) Biondic, M.C.; Erra-Balsells, R. J. Chem. Soc., Perkin Trans. 2 1997, 1323. (g) Biondic, M. C.; Erra-Balsells, R. J. Chem. Res. (S) 1998, 114. (h) Tarzi, O. I.; Erra-Balsells, R. J. Photochem. Photobiol B: Biology 2005, 80, 29. (i) Tarzi, O. I.; Erra-Balsells, R. J. Photochem. Photobiol B: Biology 2006, $82,79$.

2. (a) Nonami, H.; Fukui, S.; Erra-Balsells, R. J. Mass Spectrom. 1997, 32, 287. (b) Nonami, H.; Tanaka, K.; Fukuyama, Y.; Erra-Balsells, R. Rapid Commun. Mass Spectrom. 1998, 12, 285. (c) Nonami, H.; Orcoyen, M.; Fukuyama, Y.; Biondic, M. C.; Erra-Balsells, R. An. Asoc. Quim. Argentina 1998, 86, 81. (d) Tanaka, K.; Nonami, H.; Fukuyama, Y.; Erra-Balsells, R. Proceedings of the $46^{\text {th }}$ ASMS Conference on Mass Spectrometry and Allied Topics 1998, 1016. (e) Nonami, H.; Wu, F.; Thummel, R. P.; Fukuyama, Y.; Yamaoka, H.; Erra-Balsells, R. Rapid Commun. Mass Spectrom. 2001, 15, 2354. (f) Erra-Balsells, R.; Nonami, H. Environ. Control in Biol. 2002, 40, 55. (g) Erra-Balsells, R.; Nonami, H. ARKIVOC 2003, (x), 517. (h) Fukuyama, Y.; Kolender, A. A.; Nishioka, M.; Matulewicz, M. C.; Erra-Balsells, R.; Nonami, H.; Cerezo, A. S. Rapid Commun. Mass Spectrom. 2005, 19, 349.

3. Turro, N. J. Modern Molecular Photochemistry, Benjamin: Menlo Park, 1978.

4. (a) Birks, J. B. Photophysics of Aromatic Molecules, Wiley Interscience: New York, 
1970. (b) Lakowicz, J. R. Principles of Fluorescence Spectroscopy, Plenum: New York, 1983.

5. Karas, M.; Hillemkamp, F. Anal. Chem. 1988, 60, 2299.

6. Beavis, R. C.; Chait, B. T. Rapid Commun. Mass Spectrom. 1989, 3, 432.

7. Schlag, E. W. Time-of-Flight Mass Spectrometry and Its Applications, Elsevier: New York, 1994.

8. Gross, M. L., Ed. Mass Spectrometry in Biological Sciences: A Tutorial, NATO ASI Series; Kluwer Acad. Pub: London, 1990.

9. Beavis, R. C.; Chait, B. T. Methods Enzymol. 1996, 270, 519.

10. Plummer, B. F.; Steffen, L. K.; Braley, T. L.; Reese, W. G.; Zych, K.; van Dyke, G.; Tulkey, B. J. Am. Chem. Soc. 1993, 115, 11543.

11. Lewitzka, F.; Lohmannsroben, H. G. J. Photochem. Photobiol. A: Chemistry 1991, 61, 191.

12. Cowan, D. O.; Drisko, R. L. Elements of Organic Photochemistry, Plenum Press: NY, 1976, pp. $250-259$.

13. Glynn, S. P.; Azumi, T.; Kinishita, M. Molecular Spectroscopy of the Triplet State, Prentice Hall: Englewoods Cliffs, NJ, 1969.

14. Chandra, A. K.; Turro, N. J.; Lyooms, A. L.; Stone, P. J. Am. Chem. Soc. 1978, 100, 4964.

15. Robinson, G. W.; Frosch, R. P. J. Chem. Phys. 1962, 38, 1187.

16. McClure, P. S. J. Chem. Phys. 1949, 17, 905.

17. Aullo, J. M.; Tomas Vert, F. An. Quim. 1979, 75, 11.

18. Pardo, A.; Reyman, D.; Martin, E.; Poyato, J. L. M.; Camacho, J. J.; Hidalgo, J.; Sanchez, M. J. Lumin. 1988, 42, 163.

19. Varela, A. P.; Burrows, H. D.; Douglas, P.; Miguel, M. da G. J. Photochem. Photobiol. A: Chemistry 2001, 146, 29.

20. Murov, L. S.; Carmichael, I.; Hug, G. L. Handbook of Photochemistry, Marcel Dekker: $\mathrm{NY}, 2^{\text {nd }}$ Edn, 1993.

21. Adams, J. F.; Mantulin, W. W.; Huber, J. R. J. Am. Chem. Soc. 1973, 94, 5477.

22. Ponce, M. A.; Erra-Balsells, R. J. Heterocycl. Chem. 2001, 38, 1071; Ponce, M. A.; Tarzi, O. I.; Erra-Balsells, R. J. Heterocycl. Chem. 2003, 40, 419.

23. (a) Bonesi, S. M.; Erra-Balsells, R. J. Lumin. 2001, 93, 51. (b)Bonesi, S. M.; ErraBalsells, R. J. Lumin. 2002, 27, 83. 